Revista Brasileira de Agricultura Irrigada v.10, nº.2, p. 544 - 552, 2016

ISSN 1982-7679 (On-line)

Fortaleza, CE, INOVAGRI - http://www.inovagri.org.br

DOI: $10.7127 /$ rbai.v10n200399

Protocolo 399.16 - 22/01/2016 Aprovado em 14/04/2016

\title{
PRODUÇÃO DE BIOMASSA NO FEIJOEIRO COMUM EM FUNÇÃO DA REPOSIÇÃO HÍDRICA E DA FORMULAÇÃO COM NPK
}

\author{
Wilker Alves Morais ${ }^{1}$, Frederico Antonio Loureiro Soares ${ }^{2}$, Fernando Nobre Cunha ${ }^{3}$, Vitor \\ Marques Vidal $^{3}$, Nelmício Furtado da Silva ${ }^{3}$, Marconi Batista Teixeira ${ }^{4}$
}

\section{RESUMO}

O feijão além de ser um dos alimentos básicos da população, também é fonte de proteína para as classes carentes da população. Objetivou-se avaliar o efeito de diferentes lâminas de irrigação e da adubação com nitrogênio, potássio e fósforo na produção de matéria seca da folha, do caule e da parte aérea do feijão comum. O delineamento experimental adotado foi o de blocos ao acaso, analisado em esquema de parcelas subdivididas 4 × 7 totalizando 28 tratamentos com três repetições compondo um experimento com 84 unidades experimentais. Os tratamentos foram compostos por quatro lâminas de irrigação e sete formulações de adubações. Foram avaliadas as produções de matéria seca da folha, matéria seca do caule e matéria seca da parte aérea aos 15, 30, 45 e 90 DAS. A formulação 100:100:200\% de NPK resultou em melhores resultados para matéria seca da parte aérea e a formulação 100:100:100\% de NPK foi a que apresentou menor matéria seca da parte aérea aos 45 e 90 dias após a semeadura, na reposição hídrica de $100 \%$. A lâmina de irrigação ideal para a matéria seca da parte aérea do feijão depende do tipo de formulação utilizada.

Palavras-chave: Phaseolus vulgaris, reposição hídrica, NPK

\section{BIOMASS PRODUCTION AT THE BEAN IN FUNCTION OF WATER REPLACEMENT AND OF THE FORMULATION WITH NPK}

\begin{abstract}
The beans in addition to being one of the staple foods of the population, is also a source of protein for the underprivileged classes of the population. The objective was to evaluate the effect of different irrigation and fertilization with nitrogen, potassium and phosphorus in the production of dry matter of leaf, stem and of shoot of bean. The experimental design adopted was the randomized blocks, analyzed in a split plot scheme $4 \times 7$ totaling 28 treatments with

\footnotetext{
${ }^{1}$ Doutorando em Ciências Agrárias - Agronomia, Instituto Federal Goiano - Campus Rio Verde, Rodovia Sul Goiana, Km 01, CEP: 75.901-170, Rio Verde - GO, e-mail: wilker.alves.morais@gmail.com

${ }^{2}$ Eng. Agrônomo, Prof. Dr. em Agronomia, IFGoiano - Campus Rio Verde, e-mail: fredalsoares@ hotmail.com

3 Doutorando em Ciências Agrárias - Agronomia, IFGoiano - Campus Rio Verde, e-mail: fernandonobrecunha@hotmail.com, vmarquesvidal@gmail.com, nelmiciofurtado@gmail.com

${ }^{4}$ Eng. Agrônomo, Prof. Dr. em Agronomia, IFGoiano - Campus Rio Verde, e-mail: marconibt@ gmail.com
} 
three replications composing an experiment with 84 experimental units. The treatments were composed of four water application and fertilization seven formulations. Were evaluated the dry matter production of leaf, stem dry matter and dry matter of the shoot at 15, 30, 45 and 90 DAS. Formulation 100:100:200\% of NPK resulted in better results for dry matter of shoot and the formulation 100:100:100\% of NPK demonstrated the lowest dry matter of shoot at 45 and 90 days after sowing, in water application $100 \%$. The application water ideal for dry matter of the shoot of the bean depends on the type of formulation used.

Keywords: Phaseolus vulgaris, water application, NPK

\section{INTRODUÇÃO}

O feijão além de ser um dos alimentos básicos da população, também é fonte de proteína para as classes carentes da população, sendo que no Brasil o consumo dessa leguminosa atingiu cerca de 17,06 kg habitante ${ }^{1}$ ano $^{-1}$ (BARBOSA et al., 2012).

Devido à baixa fertilidade dos solos brasileiros em geral, onde se conduzem plantios de feijão, a adubação e a irrigação exercem papéis importantes, uma vez que contribuem para $\mathrm{o}$ aumento da produtividade $\mathrm{e}$ desenvolvimento da cultura (OLIVEIRA et al., 2004).

A adubação química, com recomendações de aplicação de fósforo, potássio e nitrogênio, tem sido predominante, enquanto que o emprego de adubos orgânicos na cultura do feijão é pouco mencionado (ARAÚJO et al., 2000).

O manejo adequado da adubação nitrogenada representa uma das principais dificuldades da cultura do feijoeiro, visto que a sua utilização em quantidade insuficiente pode limitar o seu potencial produtivo, mesmo que outros fatores de produção sejam otimizados (SANTOS et al., 2003).

Reichert (2012) observou influência na produtividade quando se acrescenta nitrogênio, além disso também verificou que isso ocorre principalmente quando este elemento é acrescentado na cultura, como adubação de cobertura, sendo observada elevação na produtividade, mostrando que a cultura responde a esta tecnologia. $\mathrm{O}$ feijão-comum também apresenta fixação biológica de $\mathrm{N}_{2}$, mas sua eficiência de fixação é geralmente baixa, sendo assim, basicamente recomendada a adubação nitrogenada para atender às exigências das plantas (WESTERMANN et al., 1981).
Respostas acentuadas na cultura do feijão tem sido verificadas também principalmente em aplicação de fósforo e cálcio, não havendo efeito da aplicação de potássio em termos de produtividade (FARIA, 2012).

Objetivou-se avaliar o efeito de diferentes lâminas de irrigação e da adubação com nitrogênio, potássio e fósforo na produção de matéria seca da folha, do caule e da parte aérea do feijão comum.

\section{MATERIAL E MÉTODOS}

O experimento foi realizado em ambiente controlado (casa de vegetação climatizada) no Instituto Federal Goiano - Campus Rio Verde, no Sudoeste de Goiás, o solo utilizado foi caracterizado como Latossolo Vermelho distroférrico (EMBRAPA, 2006). A temperatura média do ambiente de controle foi de $27^{\circ} \mathrm{C} \pm 3$, a umidade relativa média foi de $70 \%$ $\pm 3 \mathrm{e}$ a velocidade do vento foi de $2,4 \mathrm{~km} \mathrm{~h}^{-1}$ (ventilador exaustor ligado).

A casa de vegetação utilizada possui o sistema de climatização (temperatura e umidade) por circulação e refrigeração de água, aeração controlada por exaustores, sistema de irrigação por aspersores e cortina de sombreamento. Todos esses dispositivos são automatizados e são controlados por regulagem em um painel de controle principal.

O delineamento experimental adotado foi o de blocos casualizados, analisado em esquema de parcelas subdivididas $4 \times 7$, totalizando 28 tratamentos, com três repetições, compondo um experimento com 84 unidades experimentais. As parcelas foram compostas por quatro regimes hídrico $25,50,75$ e $100 \%$ da reposição hídrica (RH). As subparcelas referem-se às sete 
formulações de adubações testadas sendo, 100:100:100; 50:100:50; 200:100:200; 50:100:100; 200:100:100; 100:100:50 e 100\%:100\%:200\% do recomendado para N:P:K conforme Novais et al. (1991). Para a formulação 100:100:100\% de NPK utilizou-se $0,68 \mathrm{~g}$ de nitrogênio, $2,4 \mathrm{~g}$ fósforo e $1,2 \mathrm{~g}$ de potássio, sendo as demais formulações definidas em função desses valores.

Para obter a irrigação recomendada utilizou-se três vasos drenos (lisímetro de drenagem) para cada $\mathrm{RH}$, que foi considerada a lâminas de 100\%; nesses drenos eram adicionadas uma determinada quantidade de água, a mesma para todos, até os vasos começarem a drenar. A água percolada encontrada nos coletores era medida em uma proveta com volume conhecido $(500 \mathrm{~mL})$ precisão de $0,5 \mathrm{~mL}$, o valor encontrado era subtraído a quantidade inicial irrigada, este procedimento foi feito para todos os nove lisímetros de drenagem onde em seguida foram realizadas suas médias. A quantidade retida no vaso foi considerada a recomendação e desses valores tinha-se as outras porcentagens de irrigação $(25,50$ e $75 \%$ da $\mathrm{RH})$.

Montou-se um sistema de irrigação localizado por gotejamento na casa de vegetação com 12 registros, que foram utilizados para controlar a água que foi inserida em cada vaso, sendo, um registro para cada tratamento e suas devidas repetições. $O$ tubo gotejador foi disposto na parte superficial dos vasos onde cada vaso recebia água de um gotejo. O controle da quantidade de água aplicada foi controlado pelo conjunto registro + manômetro de glicerina.

Os vasos utilizados tinham capacidade para $10 \mathrm{~kg}$ porém foram devidamente preenchidos com $8 \mathrm{~kg}$ com solo Latossolo Vermelho distroférrico.
Foram avaliadas as produções de matéria seca da folha (MSF), matéria seca do caule (MSC) e a matéria seca da parte aérea (MSPA) aos 15, 30, 45 e 90 dias após semeadura (DAS).

A secagem das plantas para conseguir as fitomassas secas foi realizado através do acondicionamento de folhas e caules separados de cada planta em sacos de papéis devidamente numerados, de acordo com cada tratamento, e levado a estufa de secagem com circulação e renovação de ar por 48 horas a temperatura de $65^{\circ} \mathrm{C}$ (LACERDA et al., 2009). Todos os pesos para obtenção da matéria seca foram realizados em balança com precisão de $0,01 \mathrm{~g}$.

Os dados para cada variável foram submetidos à análise de variância pelo programa estatístico SISVAR (FERREIRA, 2011), e em caso de significância pelo teste $\mathrm{F}$, foram submetidos ao teste de Tukey a 5\% de probabilidade para os tipos de formulações de adubos e análise de regressão para as reposições hídricas.

\section{RESULTADOS E DISCUSSÃO}

Na Tabela 1, observa-se o resumo da análise de variância para matéria seca das folhas (MSF) do caule (MSC) do feijoeiro submetidos a diferentes reposições hídricas $(\mathrm{RH})$ e formulações de adubações (F) aos 15, 30, 45 e 90 DAS. Os dados de MSF apresentaram diferença significativa aos 30 e 45 DAS. Analisando os tipos de formulações se observa que os resultados da MSF não foram significativos para nenhuma época avaliada. Observou-se que para o fator $\mathrm{RH}$ houve diferença significativa para MSC aos 30, 45 e 90 DAS. A formulação e a interação RH x F não foi significativo para a variável MSC em todos os DAS avaliados.

Tabela 1. Resumo da análise de variância para matéria seca da folha (MSF) e da matéria seca do caule (MSC) do feijoeiro submetido a diferentes reposições hídricas e tipos de formulações de adubação aos $15,30,45$ e 90 dias após semeadura (DAS)

\begin{tabular}{lccccccccc}
\hline & \multicolumn{6}{c}{ Quadrado médio } \\
\cline { 2 - 9 } FV & GL & \multicolumn{6}{c}{ MSF } & \multicolumn{4}{c}{ MSC } \\
\cline { 2 - 9 } & & 15 DAS & 30 DAS & 45 DAS $^{1}$ & 90 DAS $^{2}$ & $15 \mathrm{DAS}^{1}$ & 30 DAS & $45 \mathrm{DAS}^{1}$ & $90 \mathrm{DAS}^{2}$ \\
\hline RH & 3 & $1,99^{\text {ns }}$ & $1,56^{*}$ & $2,06^{* *}$ & $1,99^{\text {ns }}$ & $0,017^{\text {ns }}$ & $0,74^{*}$ & $1,22^{*}$ & $7,54^{* *}$ \\
Bloco & 2 & $0,53^{\text {ns }}$ & $0,17^{\text {ns }}$ & $2,27^{*}$ & $0,53^{\text {ns }}$ & $0,007^{\text {ns }}$ & $0,38^{\text {ns }}$ & $1,89^{\text {ns }}$ & $0,16^{\text {ns }}$
\end{tabular}


Morais et al.

\begin{tabular}{lccccccccc} 
Resíduo a & 6 & 0,79 & 0,35 & 0,11 & 0,79 & 0,012 & 0,1 & 0,29 & 0,37 \\
\hline F & 6 & $0,13^{\text {ns }}$ & $0,20^{\text {ns }}$ & $0,17^{\text {ns }}$ & $0,13^{\text {ns }}$ & $0,010^{\text {ns }}$ & $0,05^{\text {ns }}$ & $0,27^{\text {ns }}$ & $0,26^{\text {ns }}$ \\
RH x F & 18 & $0,20^{\text {ns }}$ & $0,12^{\text {ns }}$ & $0,17^{\text {ns }}$ & $0,20^{\text {ns }}$ & $0,010^{\text {ns }}$ & $0,03^{\text {ns }}$ & $0,13^{\text {ns }}$ & $0,16^{\text {ns }}$ \\
Resíduo b & 48 & 0,18 & 0,12 & 0,11 & 0,18 & 0,014 & 0,04 & 0,16 & 0,12 \\
\hline CV a $(\%)$ & & 32,82 & 14,3 & 10,27 & 32,82 & 9,06 & 8,24 & 14,41 & 20,26 \\
CV b (\%) & 15,78 & 8.58 & 10,04 & 15,78 & 9,75 & 5,39 & 10,68 & 11,76 \\
\hline
\end{tabular}

Formulação"

Médias

\begin{tabular}{|c|c|c|c|c|c|c|c|c|}
\hline \multirow{3}{*}{ F1-100:100:100\% } & \multirow{2}{*}{\multicolumn{8}{|c|}{ 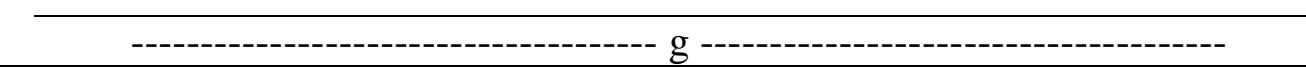 }} \\
\hline & & & & & & & & \\
\hline & 1,61 & 4,06 & 10,23 & 6,82 & 1,48 & 3,88 & 12,31 & 7,32 \\
\hline $\mathrm{F} 2-50: 100: 50 \%$ & 1,62 & 4,12 & 10,15 & 6,92 & 1,48 & 3,77 & 14,52 & 8,8 \\
\hline F3- 00:100:200\% & 1,83 & 4,14 & 10,55 & 6,52 & 1,69 & 3,82 & 15,36 & 7,94 \\
\hline F4 -50:100:100\% & 1,72 & 4,29 & 10,12 & 7,24 & 1,6 & 3,83 & 15,2 & 8,79 \\
\hline F5-200:100:100\% & 1,91 & 4,38 & 11,2 & 6,38 & 1,65 & 3,98 & 14,22 & 8,15 \\
\hline F6-100:100:50\% & 1,63 & 4,1 & 10,45 & 5,63 & 1,52 & 3,8 & 13,9 & 9,27 \\
\hline F7-100:100:200\% & 1,68 & 4,01 & 12,6 & 7,04 & 1,61 & 3,8 & 15,52 & 10,33 \\
\hline
\end{tabular}

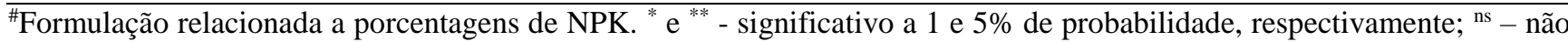
significativo a 5\% de probabilidade pelo teste F. GL - Grau de liberdade. RH - Reposição hídrica. F - Tipo de formulação. RH x F - Interação RH x F. ${ }^{1}$ Dados transformados em Raiz de X. ${ }^{2}$ Dados transformados em Raiz de X + $1 .{ }^{3}$ - Médias apresentadas sem transformação.

Para MSF tem o acréscimo de 5,5 e $21,2 \%$ para cada aumento de $25 \%$ na $\mathrm{RH}$, para os 30 e 45 DAS, respectivamente (Figura 1), esses resultados corroboram com os obtidos por Gomes et al. (2000). Silva et al. (2012) analisando MSF do feijoeiro pelo potencial matricial de irrigação, verificaram que quanto mais água disponível maior o rendimento da matéria seca foliar, porém, obteve-se uma resposta quadrática para a fase vegetativa e linear para reprodutiva.

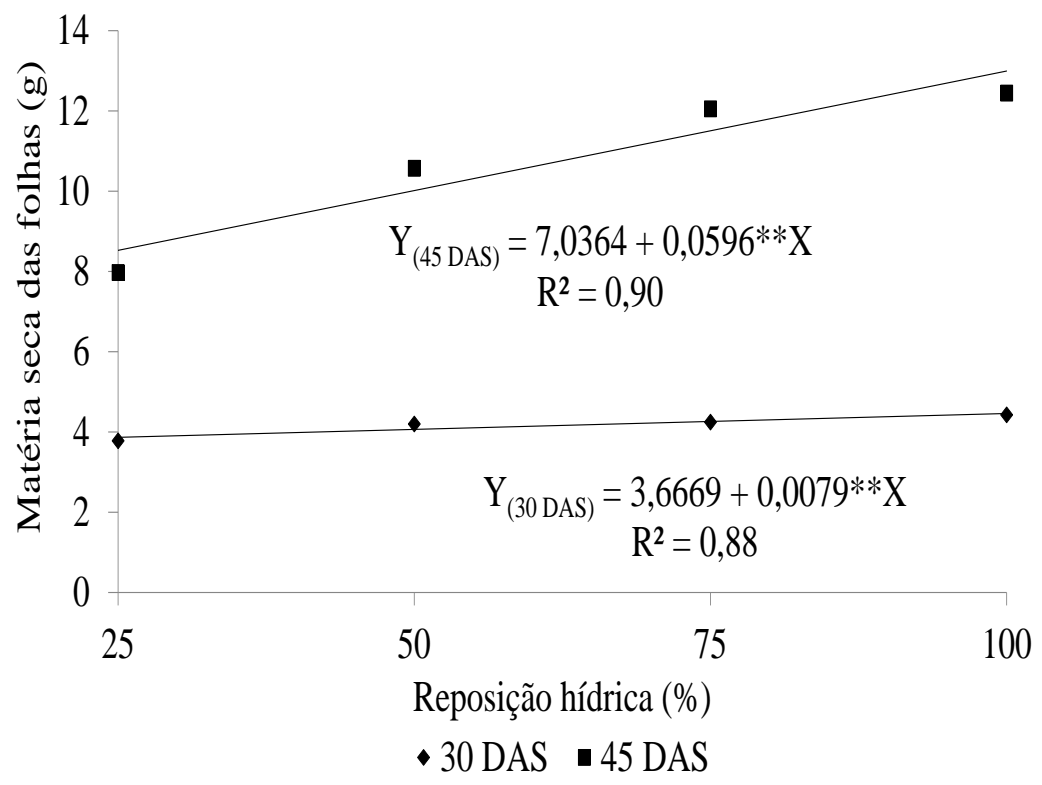

Figura 1. Matéria seca das folhas do feijoeiro aos 30 e 45 dias após semeadura em função da reposição hídrica.

Os resultados de MSC avaliados em todos os DAS mostraram crescimento linear, ou seja, para cada aumento de $1 \%$ de RH a MSC apresentou um acréscimo de 0,$14 ; 0,31$ e $0,85 \%$ na $\mathrm{RH}$, aos 30 , 45 e 90 DAS, respectivamente (Figura 2). Arf et al. 
(2004) avaliando manejo de irrigação no feijoeiro (lâminas de 89, 125 e $161 \mathrm{~mm}$ ) verificaram maior matéria seca para a lâmina de $125 \mathrm{~mm}$.

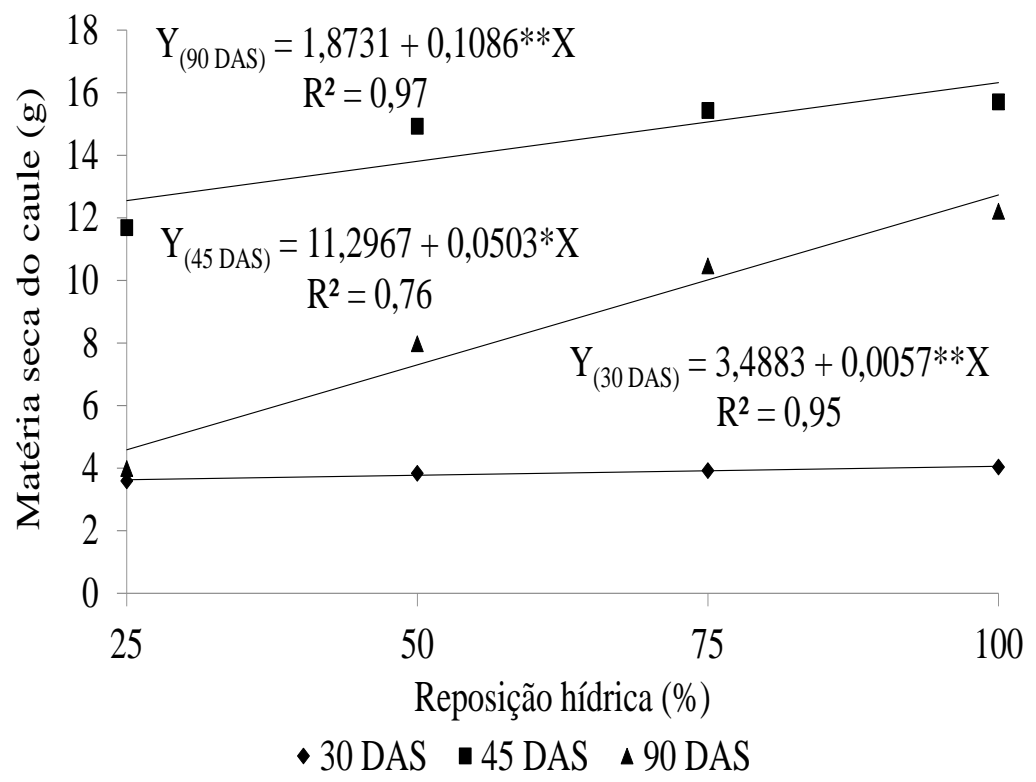

Figura 2. Matéria seca do caule do feijoeiro aos 30, 45 e 90 dias após semeadura em função da reposição hídrica.

Na Tabela 2, encontra-se o resumo da análise de variância para matéria seca da parte aérea (MSPA) do feijoeiro submetido a diferentes reposições hídricas (RH) e tipos de formulações de adubação (F) aos 15, 30, 45 e 90 dias após a semeadura (DAS). Verificou-se que houve significância de $1 \%$ de probabilidade aos 45 e 90 DAS para MSPA, já aos 30 DAS observou-se significância de $5 \%$ de probabilidade. Não houve diferença significativa para os $\mathrm{F}$, porém, houve significância de $5 \%$ para a interação $\mathrm{RH}$ x $F$ aos 90 DAS da MSPA.

Tabela 2. Resumo da análise de variância para matéria seca da parte aérea (MSPA) do feijoeiro submetido a diferentes reposições hídricas e tipos de formulações de adubação aos 15, 30, 45 e 90 dias após semeadura (DAS)

\begin{tabular}{|c|c|c|c|c|c|}
\hline \multirow{3}{*}{ Fonte Variação } & \multirow{3}{*}{ GL } & \multicolumn{4}{|c|}{ Quadrado Médio } \\
\hline & & \multicolumn{4}{|c|}{ MSPA } \\
\hline & & $15 \mathrm{DAS}^{1}$ & 30 DAS & $45 \mathrm{DAS}^{1}$ & $90 \mathrm{DAS}^{2}$ \\
\hline RH & 3 & $0,03^{\mathrm{ns}}$ & $4,46^{*}$ & $3,16^{* *}$ & $13,67^{* *}$ \\
\hline Bloco & 2 & $0,02^{\mathrm{ns}}$ & $1,07^{\mathrm{ns}}$ & $3,85^{*}$ & $0,14^{\mathrm{ns}}$ \\
\hline Resíduo a & 6 & 0,03 & 0,81 & 0,31 & 1,14 \\
\hline $\mathrm{F}$ & 6 & $0,02^{\mathrm{ns}}$ & $0,40^{\mathrm{ns}}$ & $0,32^{\mathrm{ns}}$ & $0,33^{\mathrm{ns}}$ \\
\hline $\mathrm{RH} \times \mathrm{F}$ & 18 & $0,02^{\mathrm{ns}}$ & $0,26^{\mathrm{ns}}$ & $0,22^{\mathrm{ns}}$ & $0,38^{*}$ \\
\hline Resíduo b & 48 & 0,02 & 0,26 & 0,19 & 0,18 \\
\hline $\mathrm{CV}$ a $(\%)$ & & 10,1 & 11,3 & 11,36 & 23,12 \\
\hline
\end{tabular}




\begin{tabular}{lcccr} 
CV b (\%) & 9,48 & 6,39 & 8,93 & 9,19 \\
\hline \multicolumn{5}{c}{ Médias } \\
Formulação ${ }^{\#}$ & \multicolumn{5}{c}{. } \\
F1- 100:100:100\% & 3,09 & 7,94 & 22,54 & 20,35 \\
F2-50:100:50\% & 3,11 & 7,9 & 24,68 & 23,39 \\
F3- 200:100:200\% & 3,52 & 7,97 & 25,91 & 20,92 \\
F4-50:100:100\% & 3,32 & 8,13 & 25,32 & 22,47 \\
F5- 200:100:100\% & 3,56 & 8,36 & 25,43 & 20,89 \\
F6- 100:100:50\% & 3,16 & 7,9 & 24,36 & 22,89 \\
F7- 100:100:200\% & 3,29 & 7,82 & 28,12 & 24,76
\end{tabular}

${ }^{\#}$ Formulação relacionada a porcentagens de NPK. ${ }^{*} \mathrm{e}^{* * *}$ - significativo a 1 e $5 \%$ de probabilidade, respectivamente; ${ }^{\text {ns }}$ - não significativo a 5\% de probabilidade pelo teste F. GL - Grau de liberdade. RH - Reposição hídrica. F - Tipo de formulação. RH x F - Interação RH x F. ${ }^{1}$ Dados transformados em Raiz de X. ${ }^{2}$ Dados transformados em Raiz de X + $1 .{ }^{3}$ Médias apresentadas sem transformação.

Na Figura 3, verifica-se a MSPA em função da RH aos 30 e 45 dias após semeadura; observou-se que houve um comportamento linear em ambos os dias após semeadura. Observou-se uma diferença de aproximadamente 12 e $28 \%$ entre a reposição hídrica de 25 e $100 \%$, na matéria seca da parte aérea do feijoeiro aos 30 e 45 dias após semeadura, respectivamente. Gonçalves (2013) verificou que o déficit aplicado sob índice de intensidade de estresse hídrico de 53\%, ocasionou reduções de 49,65\% para massa seca da folha, $21,16 \%$ para massa seca do caule e redução de 33,09\% para massa seca total.

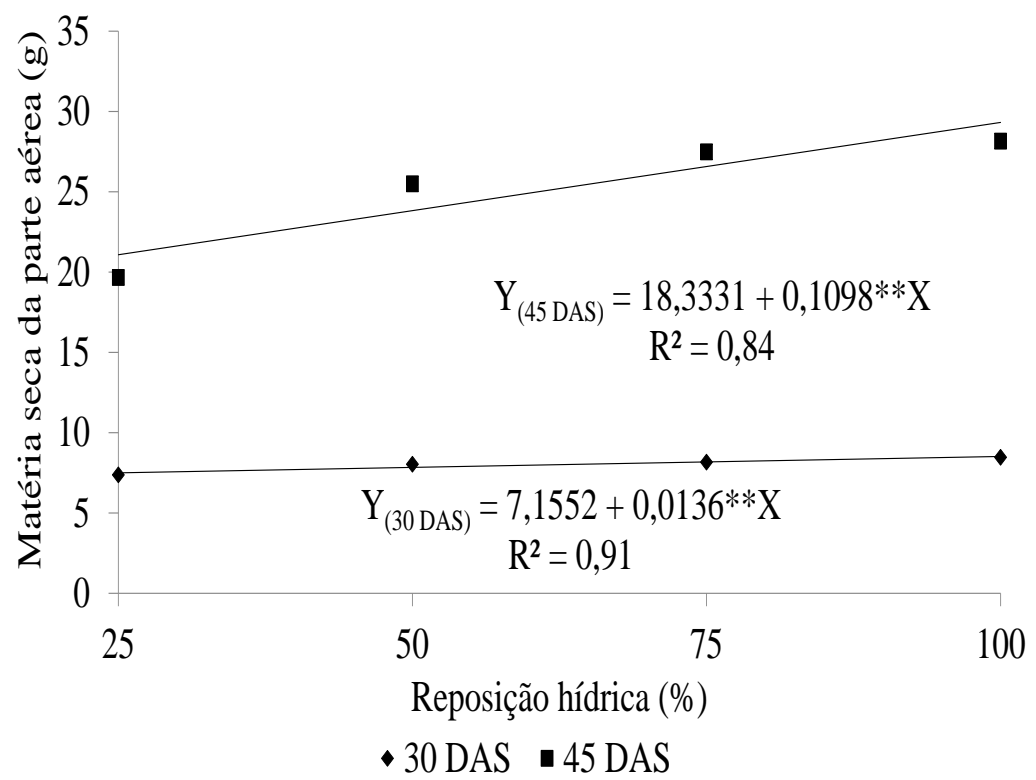

Figura 3. Matéria seca da parte aérea do feijoeiro aos 30 e 45 dias após semeadura em função da reposição hídrica.

Na Figura 4, tem-se o desdobramento da reposição hídrica dentro de cada tipo de formulação para matéria seca da parte aérea do feijoeiro aos 90 dias após semeadura (DAS). $\mathrm{Na}$ MSPA, as equações de regressões estimaram o aumento de 4,75 e $15 \%$ para cada acréscimo de $25 \%$ na $\mathrm{RH}$ aos 30 e 45 DAS, respectivamente. Mendes et al. (2007) também verificaram que o estresse hídrico determinou reduções na matéria seca da parte 
aérea. Silva et al. (2012) encontraram resultados quadráticos avaliando o potencial matricial e quanto maior a disponibilidade de água maior a MSPA.

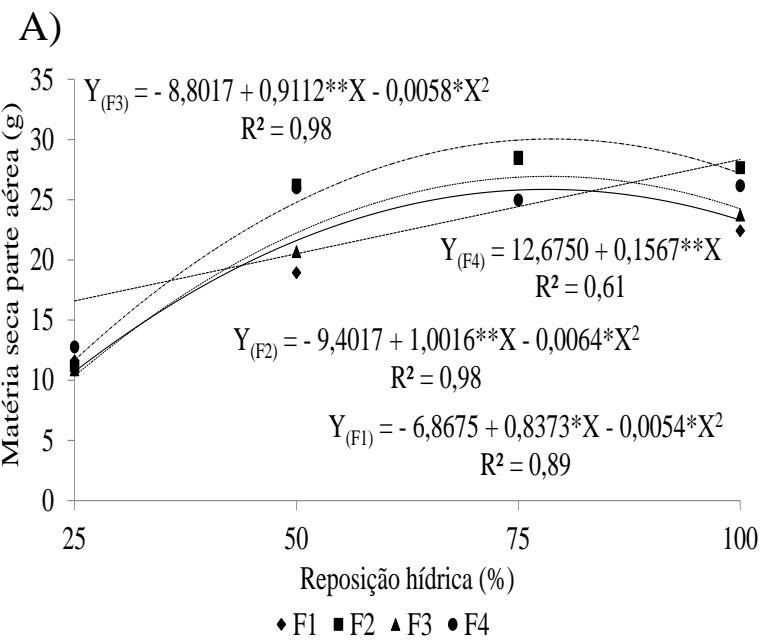

B)

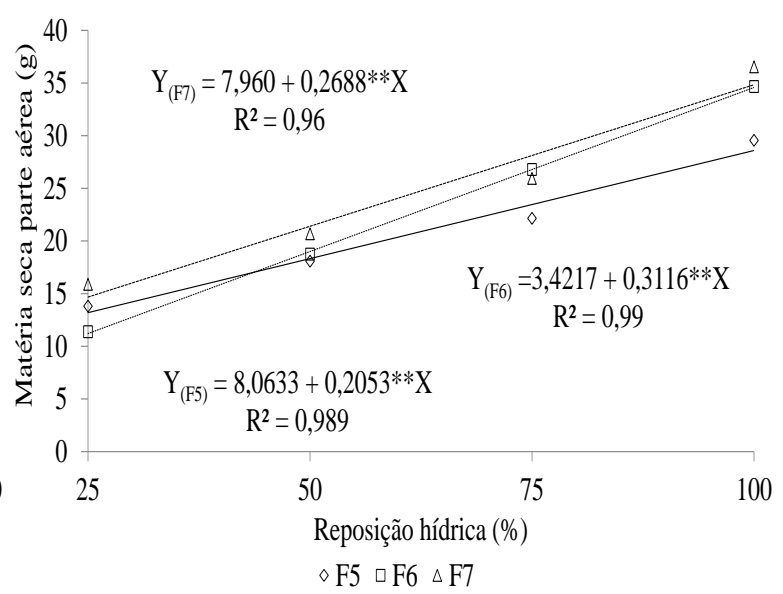

Figura 4. Matéria seca da parte aérea do feijoeiro aos 90 dias após semeadura em função da reposição hídrica para a formulação F1, F2, F3, F4 (A), F5, F6 e F7 (B).

Observa-se que os resultados demonstram comportamento quadrático para as formulações F1, F2 e F3 (Figura 4A), já para as demais formulações (F4, F5, F6 e F7) houve um comportamento linear. De acordo com as equações de regressões, a MSPA das plantas adubadas com as formulações F1, F2 e F3 apresentaram crescimento até reposição hídrica de 77,5, 78,2 e 78,5\%, respectivamente, e após estes valores verificaram decréscimos de 10,7, 10,2 e $9,9 \%$ quando comparado com a $\mathrm{RH}$ de $100 \%$, respectivamente. Para as demais formulações F4, F5, F6 e F7, estimou-se acréscimos de 1,$2 ; 2,5 ; 9,1$ e 3,4\% na MSPA para cada aumento de $1 \%$ na $\mathrm{RH}$, respectivamente (Figura 4A e B).

Parizi (2007) observou que a maior produção de grãos para a cultura do feijão foi obtida na estratégia de irrigação de $80 \%$, que apresentou os valores mais elevados dos componentes número de vagens por planta e massa seca total.

Na Tabela 3, tem-se o desdobramento do tipo de formulação (F) dentro de cada reposição hídrica $(\mathrm{RH})$ para matéria seca da parte aérea (MSPA) do feijoeiro aos 90 dias após semeadura (DAS).

Tabela 3. Desdobramento do tipo de formulação dentro de cada reposição hídrica para matéria seca da parte aérea do feijoeiro aos 90 dias após semeadura (DAS)

\begin{tabular}{lcccc}
\hline \multicolumn{2}{c}{ Tipo de Formulação $^{1}$} & \multicolumn{4}{c}{ Reposição hídrica (\%) $^{25}$} & 50 & 75 & 100 \\
\cline { 2 - 5 } F1 - 100:100:100\% & $11,61 \mathrm{a}$ & $18,93 \mathrm{a}$ & $28,48 \mathrm{a}$ & $22,41 \mathrm{~b}$ \\
F2 -50:100:50\% & $11,18 \mathrm{a}$ & $26,21 \mathrm{a}$ & $28,52 \mathrm{a}$ & $27,66 \mathrm{ab}$ \\
F3 - 200:100:200\% & $10,86 \mathrm{a}$ & $20,69 \mathrm{a}$ & $28,42 \mathrm{a}$ & $23,72 \mathrm{~b}$ \\
F4 -50:100:100\% & $12,76 \mathrm{a}$ & $25,98 \mathrm{a}$ & $24,97 \mathrm{a}$ & $26,16 \mathrm{ab}$ \\
F5 - 200:100:100\% & $13,80 \mathrm{a}$ & $18,07 \mathrm{a}$ & $22,15 \mathrm{a}$ & $29,55 \mathrm{ab}$ \\
F6 - 100:100:50\% & $11,38 \mathrm{a}$ & $18,75 \mathrm{a}$ & $26,78 \mathrm{a}$ & $34,66 \mathrm{a}$ \\
F7 - 100:100:200\% & $15,88 \mathrm{a}$ & $20,68 \mathrm{a}$ & $25,94 \mathrm{a}$ & $36,53 \mathrm{a}$ \\
\hline
\end{tabular}

${ }^{1}$ Formulação relacionada a porcentagens de NPK. Médias seguidas pela letra na vertical não diferem entre si pelo teste de Tukey a 5\% de probabilidade. 
Verificou-se que houve diferença significativa para MSPA, apenas para a RH de 100\%. As formulações F6 e F7, não apresentaram diferença significativas, no entanto a MSPA destas formulações foram $35,1 \%$, maior do que a verificada nas formulações F1 e F3. As formulações F1 e F3 não apresentaram diferença significativa para as formulações F2, F4 e F5. A formulação 100:100:200\% de NPK resultou em melhores resultados para matéria seca da parte aérea e a formulação 100:100:100\% de NPK foi a que apresentou menor matéria seca da parte aérea aos 45 e 90 dias após a semeadura, na reposição hídrica de $100 \%$.

\section{CONCLUSÕES}

As formulações não influenciaram na produção de biomassa do feijão, exceto para a produção de biomassa seca da parte aérea aos 90 dias, quando verificou-se que as formulações 100:100:100 e 200:100:200\% de NPK resultaram nos menores valores dessa variável.

A lâmina de irrigação ideal para a matéria seca da parte aérea do feijão depende do tipo de formulação utilizada.

\section{AGRADECIMENTOS}

Ao Ministério da Ciência e Tecnologia (MCT), Conselho Nacional de Desenvolvimento Científico e Tecnológico (CNPq), a Coordenação de Aperfeiçoamento de Pessoal de Nível Superior (Capes), a Fundação de Amparo à Pesquisa de Goiás (FAPEG) e ao Instituto Federal Goiano, Campus Rio Verde, pelo apoio financeiro e estrutural.

\section{REFERÊNCIAS BIBLIOGRÁFICAS}

ARAÚJO, R.; MIGLIORANZA, E.; SOUZA, J. R. P. de; ENDO, R. M.; QUINTANA, J. M.; NIENHUIS, J. Concentração de cálcio em frutos de diferentes cultivares de feijão- -vagem. Horticultura Brasileira, Brasília, v. 18, p. 672673 , julho 2000
ARF, O.; RODRIGUES, R. A. F.; SÁ, M. E. de; BUZETTI, S.; NASCIMENTO, V. do. Manejo do solo, água e nitrogênio no cultivo de feijão. Pesquisa agropecuária brasileira, v.39, n.2, p.131-138, 2004.

BARBOSA, F. R.; GONZAGA, A. C. O. Informações técnicas para o cultivo do feijoeiro-comum na região central brasileira: 2011/2013 (Série Documentos). Santo Antônio de Goiás: Embrapa Arroz e Feijão, 2012. p.1520.

EMBRAPA. Sistema brasileiro de classificação de solos. Empresa brasileira de pesquisa agropecuária. Centro Nacional de Pesquisa de Solos, 2. ed. Rio de Janeiro, 2006. $306 \mathrm{p}$.

FARIA, M. T. Produtividade da cultura do feijão (Phaseolus vulgaris L.) irrigada por aspersão convencional com diferentes métodos de estimativa de lâmina de irrigação. Tese (doutorado) - Universidade Estadual Paulista, Faculdade de Ciências Agrárias e Veterinárias, Jaboticabal, 84p. 2012.

FERREIRA, D. F. Sisvar: a computer statistical analysis system. Ciência e Agrotecnologia. vol.35 $\mathrm{n}^{\circ}$ 6, p. 1039-1042, 2011.

GOMES, A. A.; ARAÚJO, A. P.; ROSSIELLO, R. O. P.; PIMENTEL, C. Acumulação de biomassa, características fisiológicas e rendimento de grãos em cultivares de feijoeiro irrigado e sob sequeiro. Pesquisa agropecuária brasileira, v.35, n.10, p.1927-1937, 2000.

GONÇALVES, J. G. R. Identificação de linhagens de feijoeiro (Phaseolus vulgaris L.) tolerantes à seca. Tese. Agricultura tropical e subtropical - Instituto agronômico - IAC. Campinas, SP, 82p., 2013.

LACERDA, M. J. R.; FREITAS, K. R.; SILVA, J. W. da. Determinação da matéria seca de forrageiras pelos métodos de microondas e convencional. Bioscience Journal, v. 25, n. 3, p. 185-190, 2009. 
MARIN, A.; SANTOS, D. M. M. dos. Interação da deficiência hídrica e da toxicidade do alumínio em guandu cultivado em hidroponia. Pesquisa agropecuária brasileira, v.43, n.10, p.1267-1275, 2008.

MENDES, R. M. S.; TÁVORA, F. J. A. F.; PITOMBEIRA, J. B.; NOGUEIRA, R. J. M. C. Relações fonte-dreno em feijão-de-corda submetido à deficiência hídrica. Revista Ciência Agronômica, v.38, n.1, p.95-103, 2007.

NOVAIS, R. F.; NEVES, J. C. L.; BARROS, N. F. de. Ensaio em ambiente controlado. In: OLIVEIRA, A. J. et al. (Coords.). Métodos de pesquisa em fertilidade do solo. Brasília, DF: Embrapa-SEA, 1991. p. 189-253.

OLIVEIRA, R. M. B.; OLIVEIRA, F. de A.; GUEDES, K. Fertilização nitrogenada e irrigação na cultura do feijão (Phaseolus vulgaris L) em casa de vegetação. Revista de biologia e ciências da terra. Vol. 4no 2, 6p. 2004.

PARIZI, A. R. C. Efeito de diferentes estratégias de irrigação sob as culturas de feijão (Phaseolus vulgaris L.) e milho (Zea mays L.) na região de Santiago, RS. Dissertação (mestrado) - Universidade Federal de Santa Maria, Centro de Ciências Rurais. Santa Maria, 2007. 124p.

REICHERT, P. Cultura do feijão e nitrogênio no sistema de produção integração lavoura pecuária. Produção Vegetal. Dissertação. Universidade Estadual do Centro-Oeste, Guarapuava-PR, 2012.

SANTOS, A. B.; FAGERIA, N. K.; SILVA, O. F.; MELO, M. L. B. Resposta do feijoeiro ao manejo de nitrogênio em várzeas tropicais. Pesq. Agropec. Bras., 38:1265-1271, 2003.

SILVA, W. G. da, CARVALHO, J. A., OLIVEIRA, E. C., REZENDE, F. C. LIMA JUNIOR, J.A. de. RIOS, G.F.A. Manejo de irrigação para o feijão-de-metro, nas fases vegetativa e produtiva, em ambiente protegido. Revista Brasileira de Engenharia Agrícola e Ambiental, v.16, n.9, p.978-984, 2012.

WESTERMANN, D. T.; KLEINKOFF, G. E.; PORTER, L. K.; LEGGETT, G. E. Nitrogen sources for been seed production. Agronomy Journal, v. 73, p. 660-664, 1981. 